\title{
Beam to Column Timber Joints with Pretensioned Bolts
}

\author{
Awaludin, A. ${ }^{1}$, Hirai, T. ${ }^{2}$, Sasaki, Y. ${ }^{2}$, Hayashikawa, T. ${ }^{3}$, and Oikawa, A. ${ }^{3}$
}

\begin{abstract}
The effects of pretension in bolts on hysteretic response of timber joints exposed to a bending had been reported by the authors, but the cyclic tests were carried out at small displacement level which might not be applicable for earthquake-resistance design. In this study, similar cyclic tests but at large displacement levels were conducted. Beam to column timber joints with steel side plates were fabricated and continuously loaded until failure. At connection, the bolts were pretension in four different magnitudes: $0 \mathrm{kN}, 5 \mathrm{kN}, 10 \mathrm{kN}$ and $15 \mathrm{kN}$. The results showed that frictional action between the steel side plates and wood member as a result of bolt pretensioning significantly increased the (frictional) hysteretic damping and the equivalent viscous damping ratio. It is obvious from the test results that the pretension force in bolts has no influence on the maximum joint resistance but decreases the joint rotational deformation.
\end{abstract}

Keywords: Beam to column joint, cyclic load, hysteretic damping, pretensioned bolt, timber joint.

\section{Introduction}

Bolts are utilized extensively in timber connections. The bolts penetrate the members and transfer the load between members by a combination of wood bearing and fastener bending. Pre-drilled hole is often made in the members with a clearance to account for misalignment or moisture-related changes. This lead-hole clearance results in low joint stiffness at initial loading stage. Under cyclic loads, loaddisplacement curve of bolted joints is typically pinched, which means that they have very little resistance around the zero displacement points $[1,2]$. Degradation of joint resistance or stiffness observed during cyclic tests reflects the developing of gaps or cavities between the bolts and the wood around them. Loaded at the same displacement level, strength degradation after three or more cycles has been found to be relatively small. Pouring epoxy resin into the voids between the over-sized hole and bolts was found to improve the joint performance since the bolts experienced little bending deformation and fatigue stress [3].

1Department of Civil and Environmental Engineering, Gadjah Mada University, Grafika 2, UGM campus, Yogyakarta 55281, INDONESIA.

E-mail: ali@tsipil.ugm.ac.id; ali.awaludin@ugm.ac.id

${ }^{2}$ Research Faculty of Agriculture, Hokkaido University, Kita 9 Nishi 9, Kita-ku, Sapporo 060-8589, JAPAN.

${ }^{3}$ Research Faculty of Engineering, Hokkaido University, Kita 13 Nishi 8, Kita-ku, Sapporo 060-8628, JAPAN.

Note: Discussion is expected before November, 1 $^{\text {st }} 2011$, and will be published in the "Civil Engineering Dimension" volume 14, number 1, March 2012.

Received 21 May 2010; revised 25 March 2011; accepted 18 April 2011.
An improved joint performance, both strength and ductility ratio, was also reported by gluing highembedding strength materials at joint shear plane, the interface between two adjacent members [4-7]. The main reason for this local reinforcement is to prevent timber splitting, which in most cases leads to failure of the connection. Some of these reinforcing materials are plywood, plybamboo, steel plate and Densified Veneer Wood (DVW). Recently, viscoelastic (VE) polymer, which is a rubber-like material, was introduced at the shear plane between gypsum sheathing to timber frame connections. Under quasistatic cyclic loads a significant increase of energy dissipation capacity of the connection was reported [8]. The VE polymer dissipates energy via sharing action across the cross section while also adding stiffness to the connection system. Improvement of seismic performance of moment-resisting bolted joints by inserting nails closer to the joint centroid than the bolts was also reported [9].

Improved static and dynamic response of steel-totimber joints due to axial pretension in bolts has been shown in our previous report [10]. The pretension is simply obtained by fastening the bolts, for example by using a torque wrench device, so that the steel plates compress the wood member in its transverse direction. Frictional resistance among the members of the joints caused by pretension substantially increased the initial slip resistance and hysteretic damping. Under cyclic loads, lateral resistance of joints with pre-tensioned bolts decreased with a lower degradation rate than that of the non-pretensioned joints. However, those improvements were based on cyclic tests in serviceability range or joint rotation up to ten percent of the ultimate joint rotation. For an earthquake-resistance design, those findings are required to be further 
examined at some higher rotation levels. The objective of this study was to investigate the effect of pretension in bolts on cyclic properties of beam to column timber joints with steel side plates under large displacement levels.

\section{Materials and Methods}

Spruce-pine-fir laminate was fabricated by bonding three laminas with resorcinol-formaldehyde resin adhesive. The average moisture content was found to be $13 \%$, while the oven dry specific gravity was 0.38 . A beam to column joint model shown in Figure 1 is composed of two glued laminated lumbers (cross section, 100 by $270 \mathrm{~mm}$ ) that were connected to each other by steel side plates of $4 \mathrm{~mm}$ thickness. Four 12 $\mathrm{mm}$ bolts were used to connect steel side plates and vertical member, while four $16 \mathrm{~mm}$ bolts were used to connect the steel plates and horizontal member. Pre-drilled hole, $1 \mathrm{~mm}$ larger than the bolt diameter, was drilled on both wood and steel members to accommodate the possible misalignment.

In this test, the lateral load generated by actuator at the top of vertical wood member has a vertical distance of $475 \mathrm{~mm}$ from the joint A or $790 \mathrm{~mm}$ from the joint $\mathrm{B}$ as shown in Figure 1.

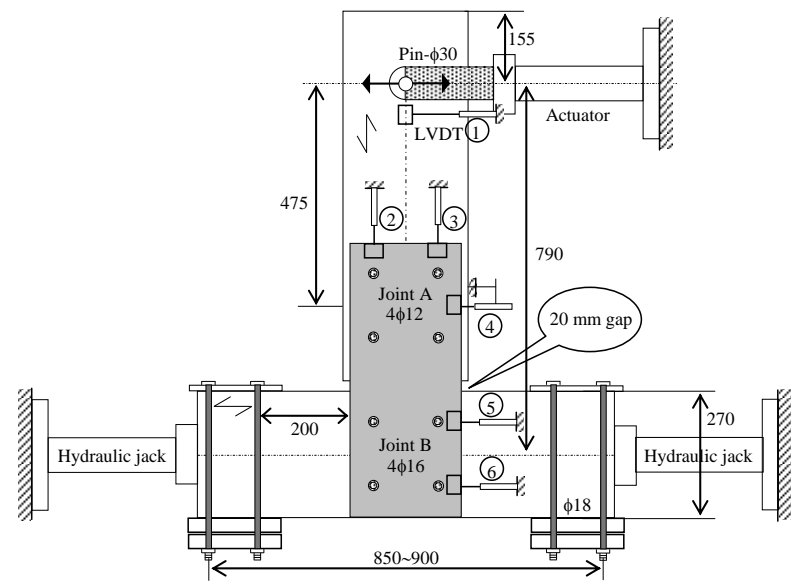

(a) Simplified test set up

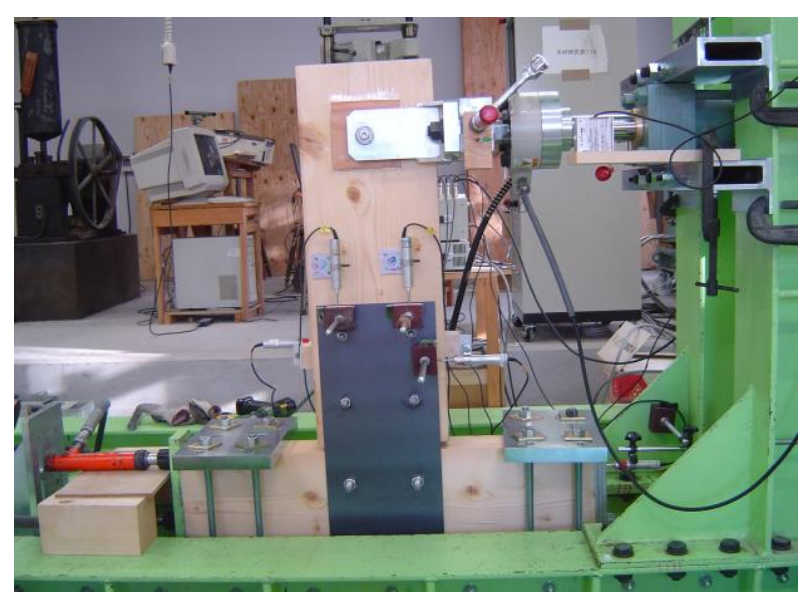

(b) Experiment photo

Figure 1. Cyclic test of beam to column joint
The applied load was controlled according to lateral displacement of the vertical wood member measured by LVDT 1. Rotational deformation of both joint A and B was evaluated based on the relative slip measurement between wood member and steel side plate (joint A: LVDT 2, 3 and 4; joint B: LVDT 5 and 6). This measurement was simultaneously performed as shown in Figure 1.b. Both ends of the horizontal member are connected to a fix support through hydraulic jacks to prevent sliding of the beam to column joint specimen during loading application.

The cyclic test protocol consisted of seven lateral displacement levels (measured by LVDT 1) from ten $\mathrm{mm}$ to $70 \mathrm{~mm}$ with an interval of ten $\mathrm{mm}$ as illustrated in Figure 2. At any displacement level, the cyclic load was repeated three times before going to the next level. Assuming that bending deformation of the vertical wood member is small and can be neglected, lateral displacement measured by LVDT 1 obviously is only the result of bending deformation of the steel side plates and both rotational deformation of the joint A and B (see Fig. 1.b). This is generally applicable in timber structures with semi-rigid joints where member deformation is relatively small compared to the deformation of their joints.

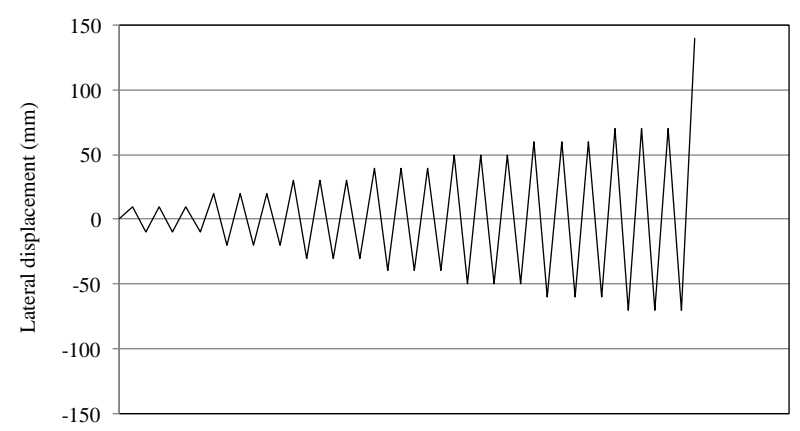

Figure 2. Displacement-controlled loading protocol of the experiment

At joint A the pretension was varied for four different levels: $0 \mathrm{kN}, 5 \mathrm{kN}, 10 \mathrm{kN}$ and $15 \mathrm{kN}$. These forces are less than the pretension of our previous study, which was $20 \mathrm{kN}$ (introducing prestressing level of $1600 \mathrm{KPa}$ or $90 \%$ of the allowable long-term end-bearing stress of spruce species [11]). For each four different pretension forces, three replicates were prepared. Thus in total, twelve specimens of beam to column joint were tested. In all specimens, a constant pretension of $20 \mathrm{KN}$ was applied to bolts at the joint $B$ so that lateral displacement of the vertical member due to rotation of the connection $B$ can be minimized. Very large pretension should not be applied since wood beneath the steel plate would crush immediately and the amount of stress loss would be significant $[12,13]$. After performing the cyclic test, the joints were loaded monotonically until partial compression between the vertical and horizontal members takes place. The applied load 
was generated using a displacement-control rate of $3.75 \mathrm{~mm} / \mathrm{min}$ in both cyclic and monotonic tests.

\section{Results and Discussions}

Typical hysteresis loop of connection between steel plates and vertical member having pretension equals to $0 \mathrm{kN}$ is shown in Figure 3.a. Although the pretension in bolts is nil, joint resistance at zero rotation points after some large rotation levels is not equal to zero. This is because of the axial force development in bolts as a result of joint deformation. When the bolt is bent, the resultant length in the initial longitudinal direction of the bolt must become shorter than the initial length. Because the bolt cannot be withdrawn, the decrease in the longitudinal length means necessarily the embedment of steel plates into the wood member. Therefore, the bolt must be subjected to an axial force. The axial force development in bolt as a result of joint deformation has been associated with "cable" or "rope" effect by many previous studies and it is substantially affected by slenderness ratio of the bolts.

Hysteresis loop of connection between steel side plates and horizontal member is presented in Figure 3.b where it is clearly seen that pretension in bolts increases the joint resistance at zero rotation points.

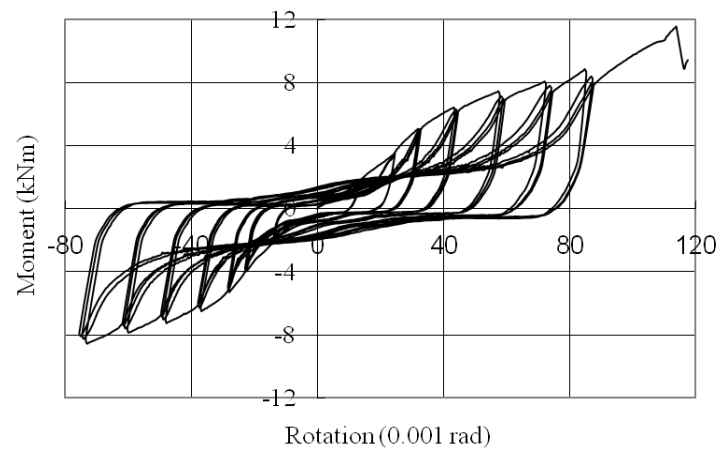

(a) Joint between steel plate and vertical member with 0 $\mathrm{kN}$ pretension force

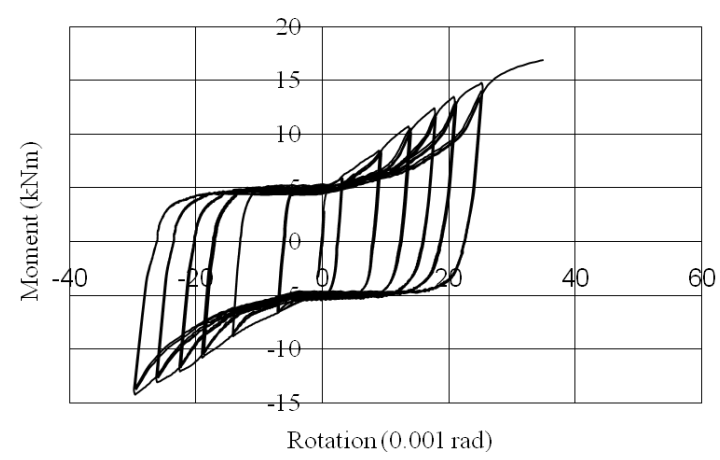

(b) Joint between steel plate and horizontal member with $20 \mathrm{kN}$ pretension force

Figure 3. Experimental hysteresis loops
The loop also shows that the joint resistance at zero rotation points is almost the same or no significant additional resistance even though the joint experiences higher rotation levels. This fact supports our previous finding that joints with a large pretension in their bolts fail with a smaller joint rotation thus giving minimum rope effect than the non-pretensioned joints [14].

Figure 4 shows the experimental hysteresis loops of connection between steel side plates and vertical member for the four different pretension forces. Very high initial stiffness (or joint resistance) due to bolt pretensioning is shown in Figures 4.b to d. Following this high initial joint resistance, interlayer slip or slip between the steel plates and wood member takes places. Joint resistance at this slip occurrence is often referred to as frictional moment resistance since it is basically related to frictional action between steel side plates and wood member. This frictional moment resistance is proportional to the magnitude of pretension force and is negligible in the non-pretensioned joints.

As shown in Figures 4.b to d, the average frictional moment resistance is about $2.16 \mathrm{kNm}, 3.71 \mathrm{kNm}$, and $5.65 \mathrm{kNm}$ for the joints with $5 \mathrm{kN}, 10 \mathrm{kN}$, and $15 \mathrm{kN}$ of pretensioning force per bolt, respectively. Figure 5 shows the relation between pretension in bolts and frictional force, which was derived based on an assumption that frictional moment resistance can be replaced by a couple of frictional force [10]. A linear relation between the pretension and joint frictional force is well indicated in Figure 5 with a friction coefficient of 0.366 . This fairly agrees with the static friction coefficient of the same steel plate and timber species reported in our previous study, which varied from 0.28 to 0.34 [14].

All the loops presented in Figure 4 indicate a sudden increase of joint resistance at bending moment equals to $10 \mathrm{kNm}$ or $11 \mathrm{kNm}$ as a result of partial compression between the vertical and horizontal members. Average maximum resistances of the joints, excluding the partial compression effect, are $10.68 \mathrm{kNm}, 10.53 \mathrm{kNm}, 10.35 \mathrm{kNm}, 10.61 \mathrm{kNm}$, respectively, for the joint with $0 \mathrm{kN}, 5 \mathrm{kN}, 10 \mathrm{kN}, 15$ $\mathrm{kN}$ of pretensioning. This result indicates that an influence of pretension in bolt is hardly obvious. However, joints with pretension in their bolts reached their maximum resistances at smaller joint rotation compared with the non-pretensioned joints as shown in Figure 4. As the cyclic loading protocol is controlled based on lateral displacement of the vertical member, the same displacement level therefore produced a smaller joint rotation in the pretensioned joints, than that in the non-pretensioned joints. 


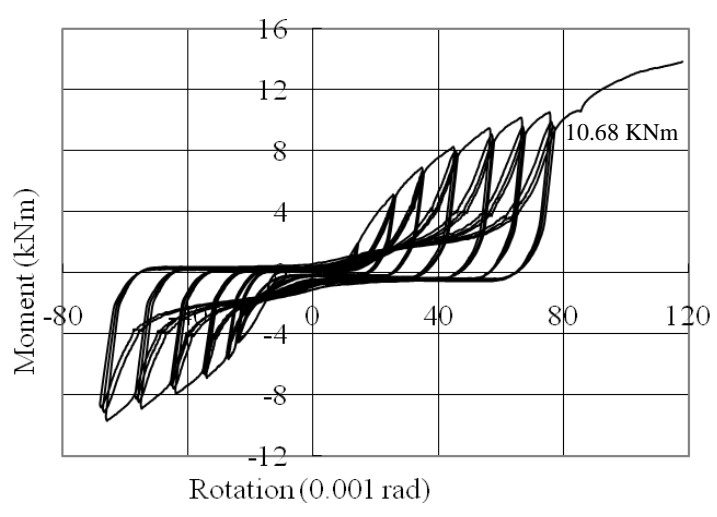

(a) No pretension force

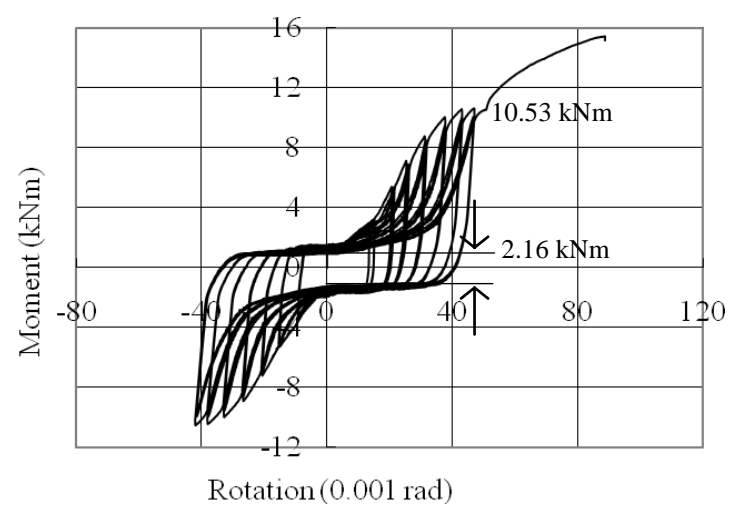

(b) $5 \mathrm{KN}$ pretension force

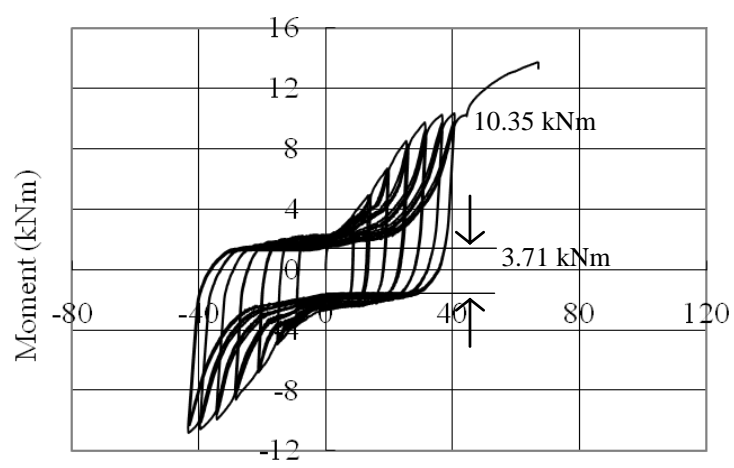

Rotation $(0.001 \mathrm{rad})$

(c) $10 \mathrm{KN}$ pretension force

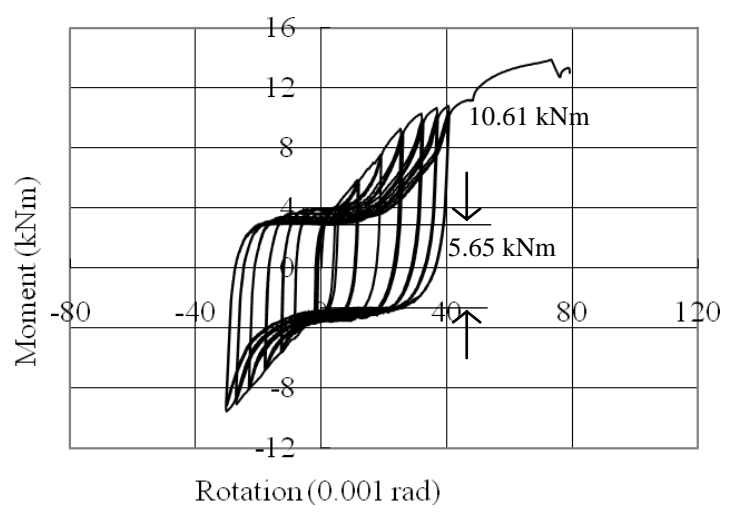

(d) $15 \mathrm{KN}$ pretension force

Figure 4. Experimental hysteresis loops of connection between steel side plates and vertical wood member for four different pretension forces

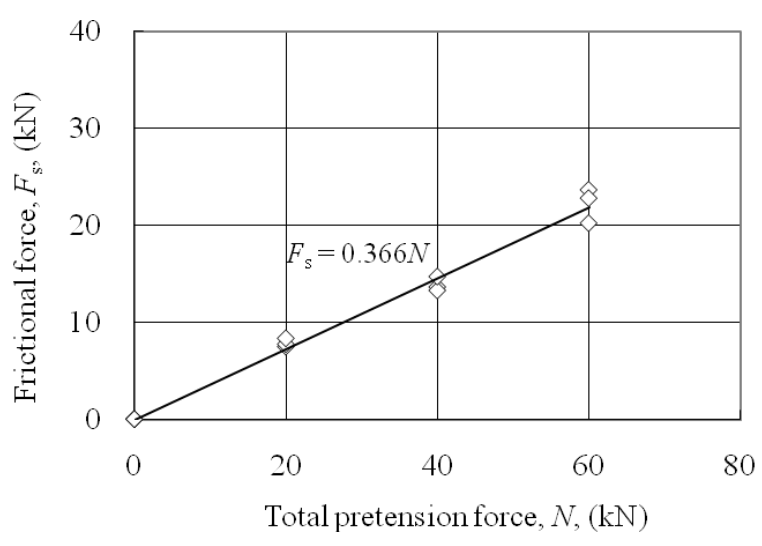

Figure 5. Relation between pretension in bolts and joint frictional resistance

The reduction of joint rotation in the case of joints with pretension in bolts must be compensated by a higher bending deformation of the steel side plates since in all specimens rotational deformation of the connection between steel side plates and horizontal wood member are apparently the same, no different treatment has been applied to this connection. In structural modeling, therefore, bending stiffness of the steel side plates should be taken into consideration to produce a more realistic deformed geometry of beam to column joints.

Cyclic rotation of (around) 0.04 rads was arbitrarily chosen to examine the influence of pretension force on hysteretic damping of the joints. The final (or stabilized) hysteresis loop at cyclic rotation of 0.04 rads is separated from the complete curve and shown in Figure 6 for both non-pretensioned and pretensioned joints. In the case of non-pretensioned joints (Fig. 6.a), the rotation of 0.04 rads is about $50 \%$ of the joint rotation that corresponds to the maximum resistance. While in the case of pretensioned joints (Fig. 6.b), this rotation level is approximately the same as the joint rotation that corresponds to the maximum resistance. The equivalent viscous damping ratio of the joints was evaluated as

$\zeta_{\text {eq }}=\frac{1}{4 \pi} \frac{E_{\mathrm{D}}}{E_{\mathrm{P}}}$

where potential energy $\left(E_{\mathrm{P}}\right)$ is the area of the triangle $\mathrm{AOB}$ and hysteretic damping $\left(E_{\mathrm{D}}\right)$ is the area enclosed by the moment rotation loop (Fig. 6.a).

Table 1 summarizes the equivalent viscous damping ratio at 0.04 rads for four different pretension forces where it is clearly indicated that increase of hysteretic damping due to pretension in bolts significantly increases the damping ratio of the joints. The damping ratio shown in Table 1 is more or less comparable with our previous report [10] in which an equivalent viscous damping ratio of 0.32 was achieved due to bolt pretension of $20 \mathrm{kN}$. 


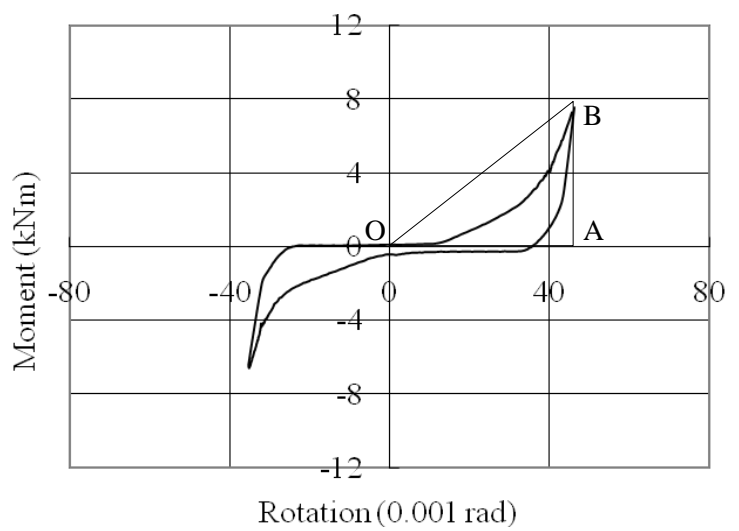

(a) No pretension force

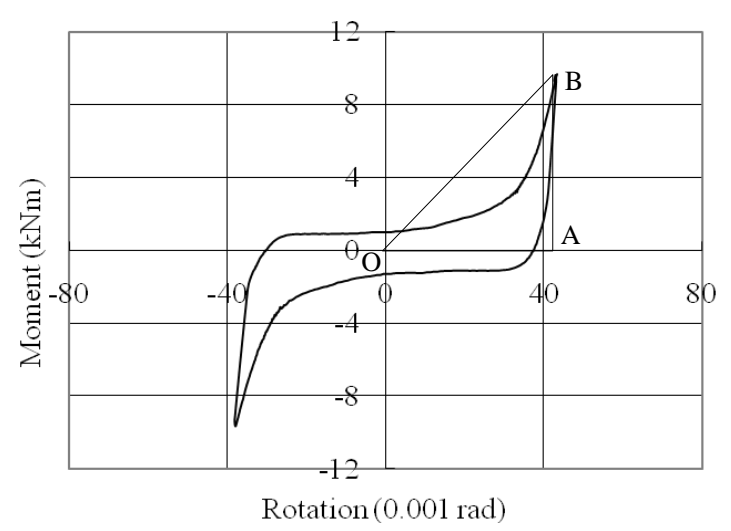

(b) $5 \mathrm{KN}$ pretension force

Figure 6. The final hysteresis loop at 0.04 rads

Table 1. Equivalent viscous damping ratio $\left(\zeta_{\mathrm{eq}}\right)$ at cyclic rotation of 0.04 rads

\begin{tabular}{ccccc}
\hline Pretension in bolt & $0 \mathrm{kN}$ & $5 \mathrm{kN}$ & $10 \mathrm{kN}$ & $15 \mathrm{kN}$ \\
\hline$\zeta_{\text {eq }}$ & 0.06 & 0.09 & 0.13 & 0.22 \\
\hline
\end{tabular}

\section{Conclusions}

Cyclic tests at large displacement levels followed by monotonic tests were carried out on beam to column timber joints to examine the influence of pretensioning in bolts on their cyclic properties. In this study, four different pretension forces: $0 \mathrm{kN}, 5$ $\mathrm{kN}, 10 \mathrm{kN}$ and $15 \mathrm{kN}$ per bolt were considered. Besides increase of initial joint slip resistance, introducing pretension force in bolt leads to a significant increase of hysteretic damping or the area enclosed by the loop and equivalent viscous damping ratio. Hysteretic damping of a pretensioned joint was substantially enlarged by frictional action between the steel side plates and wood member as a result of bolt pretensioning. The test results informed that pretension in bolts has no influence on the maximum joint resistance but substantially decreases the joint rotation.

\section{Acknowledgement}

This study was carried out when the first author (A.A.) was a post-doctoral research fellow in the Laboratory of Bridge and Structural Design Engineering, Hokkaido University, Sapporo, under the Japan Society for the Promotion of Science postdoctoral fellowship program. A continuous support from the Japan Society for the Promotion of Science from 2008 to 2010 is sincerely acknowledged.

\section{References}

1. Prion, H. and Foschi, R., Cyclic Behaviour of Dowel Type Connections, Proceedings of the Pacific Timber Engineering Conference, Gold Coast, Australia, Vol. 2, July 11-15, 1994, pp. 1925.

2. Foliente, G.C., Hysteresis Modeling of Wood Joints and Structural Systems, Journal of Structural Engineering, ASCE, Vol. 121, 1995, pp. 1013-1022.

3. Watanabe, H. and Iimura, Y., Ultimate Behavior of Bolt Joints for Glulam Bridges under Cyclic Load, Proceedings of the 9th World Conference on Timber Engineering, Portland, August 6-10, 2006. (CD-ROM)

4. Awaludin, A., Sasaki, Y., Oikawa, A., Hirai, T., and Hayashikawa, T., Moment Resisting Timber Joints with High-Strength Steel Dowels: Natural Fiber Reinforcements, Proceedings of the 11th World Conference on Timber Engineering, Trentino, June 20-24, 2010. (CD-ROM)

5. Blass, H.J., Schmid, M., Litze, H., and Wagner, B., Nail Plate Reinforced Joints with Dowel-Type Fasteners, Proceedings of the 6th World Conference on Timber Engineering, Whistler, July 31August 3, 2000. (CD-ROM)

6. Leijten, A.J.M., Ruxton, S., Prion, H., and Lam, F., Reversed-Cyclic Behavior of a Novel Heavy Timber Tube Connection, Journal of Structural Engineering, ASCE, Vol. 132, 2006, pp. 13141319.

7. Guan, Z.W. and Rodd, P.D., A Three-Dimensional Finite Element Model for Locally Reinforced Timber Joints Made with Hollow Dowel Fasteners, Canadian Journal of Civil Engineering, Vol. 27, 2000, pp. 785-797.

8. Dinehart, D.W., Blasetti, A.S., and Shenton, H.W.III., Experimental Cyclic Performance of Viscoelastic Gypsum Connection and Shear Wall, Journal of Structural Engineering, ASCE, Vol. 134, 2008, pp. 87-95. 
9. Awaludin, A., Hayashikawa, T., Oikawa, A., Hirai, T., Sasaki, Y., and Leijten, A.J.M, Seismic Properties of Moment-Resisting Timber Joints with a Combination of Bolts and Nails, Civil Engineering Dimension, Vol. 13(1), 2011, pp. 1-5.

10. Awaludin, A., Hirai, T., Hayashikawa, T., Sasaki, Y. and Oikawa, A., Effects of Pretension in Bolts on Hysteretic Response of Moment-Carrying Timber Joints, Journal of Wood Science, Vol. 54(2), 2008, pp. 114-120.

11. Architecture Institute of Japan: Standard for Structural Design of Timber Structures, Architecture Institute of Japan, Tokyo, 2006, pp. 13-14 and 400 .
12. Manrique, R.E., Stress Relaxation of Wood at Several Levels of Strain, Journal of Wood Science and Technology, Vol. 3, 1969, pp. 49-73.

13. Awaludin, A., Hirai, T., Hayashikawa, T., Sasaki, Y., and Oikawa, A., One-Year Stress Relaxation of Timber Joints Assembled with Pretensioned Bolts, Journal of Wood Science, Vol. 54(6), 2008, pp. 456-463.

14. Awaludin, A., Hirai, T., Hayashikawa, T., and Sasaki, Y., Load-Carrying Capacity of Steel-toTimber Joints with a Pretensioned Bolt, Journal of Wood Science, Vol. 54(5), 2008, pp. 362-368. 